This item was submitted to Loughborough's Research Repository by the author.

Items in Figshare are protected by copyright, with all rights reserved, unless otherwise indicated.

\title{
Pharmaceutical innovation and parallel trade
}

PLEASE CITE THE PUBLISHED VERSION

https://doi.org/10.1016/j.ijindorg.2014.02.009

\section{PUBLISHER}

(C) Elsevier

\section{VERSION}

AM (Accepted Manuscript)

\section{PUBLISHER STATEMENT}

This work is made available according to the conditions of the Creative Commons Attribution-NonCommercialNoDerivatives 4.0 International (CC BY-NC-ND 4.0) licence. Full details of this licence are available at: https://creativecommons.org/licenses/by-nc-nd/4.0/

\section{LICENCE}

CC BY-NC-ND 4.0

\section{REPOSITORY RECORD}

Bennato, Anna R., and Tommaso Valletti. 2019. "Pharmaceutical Innovation and Parallel Trade". figshare. https://hdl.handle.net/2134/25667. 


\section{Accepted Manuscript}

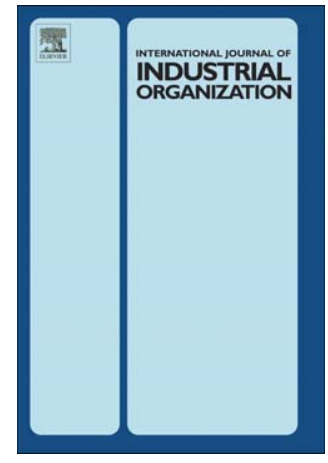

DOI:

Reference:

doi: 10.1016/j.ijindorg.2014.02.009

INDOR 2160

To appear in: $\quad$ International Journal of Industrial Organization

Received date: 11 September 2013

Revised date: $\quad 11$ February 2014

Accepted date: $\quad 21$ February 2014

Please cite this article as: Bennato, Anna Rita, Valletti, Tommaso, Pharmaceutical Innovation and Parallel Trade, International Journal of Industrial Organization (2014), doi: 10.1016/j.ijindorg.2014.02.009

This is a PDF file of an unedited manuscript that has been accepted for publication. As a service to our customers we are providing this early version of the manuscript. The manuscript will undergo copyediting, typesetting, and review of the resulting proof before it is published in its final form. Please note that during the production process errors may be discovered which could affect the content, and all legal disclaimers that apply to the journal pertain. 


\title{
Pharmaceutical Innovation and Parallel Trade*
}

\author{
Anna Rita Bennato ${ }^{\dagger}$ \\ Tommaso Valletti ${ }^{\ddagger}$
}

February 11, 2014

\begin{abstract}
This paper proposes a North-South model to study the interaction between price regulation policies and parallel trade, with a particular focus on the pharmaceutical sector. We show that, under parallel trade, R\&D investment can rise only when the South government takes into full account its impact both on investment and on the firm's decision to supply the regulated country. This arises because of a complete withdrawal from price regulation. When policy choices are endogenized, indeed the South wants to achieve this level of full commitment when it is large in size. When instead it is smaller in size, the South chooses an intermediate form of commitment whereby it anticipates its effect only on local distribution and delivery, but not on global R\&D investment. As a response to these credible levels of price control commitments, the North responds by allowing parallel imports from the South.
\end{abstract}

Keywords: IPRs, parallel trade, pharmaceutical R\&D, price regulation. JEL classification: F13; L12; O34.

\footnotetext{
${ }^{*}$ We thank the editor, two anonymous referees, Richard Friberg, Emeric Henry, Margaret Kyle, Yossi Spiegel, Stefan Szymanski, and seminar participants in Bristol, Mannheim, Paris, Rome, Stockholm, Tel Aviv, Toulouse and Zurich.

${ }^{\dagger}$ Centre for Competition Policy, University of East Anglia.

${ }^{\ddagger}$ Imperial College London, University of Rome "Tor Vergata" and CEPR.
} 


\section{Introduction}

Despite broad consensus that innovation is central to the long-run performance of an economy, there is no accord on the optimal protection of Intellectual Property Rights (IPRs). This reflects the classic trade-off between the static efficiency loss (higher prices) and dynamic gains (R\&D) associated with IPR protection. Issues related to intellectual property have been particularly contentious in the context of North-South trade, because of the possible differences in the safeguard of IPRs. Imagine a company that has a patent in the North. This company will typically want to export its product also in the South, as this enlarges its market, from which R\&D will benefit. But as the South may apply a different level of IPR protection, e.g., it may regulate the price, the North company will reassess both its $R \& D$ and its export policy, especially if the controlled price in the South can backfire in the North. A possible fall in the pace of innovation may ensue.

In this paper we study the role played by parallel imports in the international domain, with a particular emphasis on the long-run implications for the pharmaceutical sector. Parallel imports exist when there are significant price differences between countries, making this trade attractive. International price differences can be sustained only if IPRs are fully protected, making the creator the exclusive owner of her innovation. However, because parallel trade exhausts international IPRs, it makes the unauthorized import of branded drugs perfectly legal. This principle has been subject to criticism for undermining innovation, and, as a consequence, the availability of new drugs.

The conventional wisdom that parallel trade is detrimental to profits and investment has recently been challenged by Grossman and Lai (2008). They show that, in a world where international exhaustion is permitted, the pace of innovation is often faster than in one with national exhaustion. More precisely, they consider that, where parallel trade is allowed, a foreign government has incentives to apply a less stringent price control of pharmaceuticals, because it recognizes that its policy has a global impact and fosters investments. Clearly, this result depends on the ability of the foreign government to intervene before $R \& D$ has taken place. If, instead, price regulation occurs when $R \& D$ costs are sunk, price control would be more stringent, and parallel trade could kill the incentives to invest in R\&D. Anticipating tough price regulation, the patent holder may not want to deliver its drug abroad at all.

This paper develops a North-South model of parallel trade where policies towards the exhaustion of IPRs and price regulation are determined endogenously. In our model, $R \& D$ investments also arise endogenously. This combination makes our paper innovative, and its findings clarify contrasting results in the extant literature. 
We introduce a key distinction between "global" costs that companies have to sink (e.g., R\&D investments), and "local" costs to deliver a good to the South. ${ }^{1}$ Once this distinction is drawn, we consider the ability of the policy maker in the South to affect these two activities of the patent holder via drug price controls. Without any commitment (i.e., when the South government sets its regulated prices last, without taking into account neither the global nor the local investment decisions of the firm), parallel trade has no impact, since in any case the firm does not supply its good to the South. More interestingly, we show that parallel trade unambiguously reduces investment in a regime of 'partial' commitment, whereby the South government regulates the price to ensure drug delivery in the South - but after R\&D investments have already occurred. On the other hand, investments increase under 'full' commitment, when the South government moves first, that is, before both global R\&D and local delivery choices are made. When it moves first, the South government always prefers to withdraw from any price regulation. This leads to higher investment compared to when the South is insulated from the North and some price regulation would be applied. Our results thus make precise the conditions that are needed for parallel trade to have beneficial long-term effects.

When we endogenize the policy choices, we find that the South has incentives to achieve 'full' commitment only when its size is large. When it is instead smaller, a regime of 'partial' commitment yields the highest consumer surplus in the South. It follows that the South should find some credible way to achieve commitment to ensure local delivery, but not always to the extent to anticipate its full effects on global R\&D: this depends on size. In both cases, as some level of commitment is credible, price controls will never be too tough in equilibrium. This lets the North respond by adopting a system of international exhaustion.

The remainder of the paper is as follows. In the next section we discuss international exhaustion and the derogation from IPRs. In Section 3 we present our model assumptions. Section 4 describes the benchmark unregulated situation where parallel trade is immaterial. Section 5 is the central part of the paper, where we extend the benchmark by studying the impact of price regulation. In Section 6 we consider the policy game where the exhaustion of IPRs, as well as price regulation commitments, are chosen. Finally, in the last section we summarize our results and conclude.

\footnotetext{
${ }^{1}$ Goldberg (2010) shows how the coverage of distribution networks and associated ease of access to drugs in India are decisive to make any welfare assessment about the strength of IPRs.
} 


\section{International exhaustion and parallel trade}

In this section we analyze the economic issues concerning the exhaustion of property rights under the Trade-Related Aspects of Intellectual Property Rights (TRIPs) agreement. The term "parallel" emphasizes the fact that genuine products are imported across country borders creating a parallel channel to the manufacturers' authorized distribution. Even though parallel trade does not refer either to illegal or informal sector activities, or to trade in pirated or counterfeit goods, it is commonly referred to as "grey market". Parallel trade represents one of the most controversial issues in the international trade-policy ground, and has raised difficult questions, especially in the global pharmaceutical industry, which was in fact a major proponent of the TRIPs agreement.

The legal status of parallel trade differs worldwide. Within the European Union parallel imports are a legitimate trade, despite that all European members recognize IPRs as established at the international level. ${ }^{2}$ The U.S. does not allow parallel trade in pharmaceuticals, while many Asian countries do, particularly in copyrighted products (Kyle, 2009). At the international level, a first attempt to find a solution to this disputed matter has been done during the Uruguay Round negotiations. Article 6 of the TRIPs agreement states that it is possible to resort to parallel trade by the exhaustion of IPRs, however ultimately the WTO has left each member country the possibility to fix its own regime for such exhaustion. ${ }^{3}$

Some studies argue that parallel trade, where it is permitted, has not yielded the expected results in terms of convergence in price. ${ }^{4}$ Although policy papers have been written, starting with Malueg and Schwartz (1994), less attention has been paid on the long-run economic implications of parallel trade on IPRs. Scholars who believe that such arbitrage could erode IPRs, weakening the incentive for investment (e.g., Chard and Mellor, 1989; Danzon and Towse, 2003; Li and Maskus, 2006), prefer Ramseytype differential pricing as the best way to improve access to low-price drugs while still

\footnotetext{
${ }^{2}$ Parallel imports are in fact part of the "free trade" policy. Official European statistics show that in 2002 the total share of parallel imports reached $20 \%$ of the high-price pharmaceutical markets (Kanavos and Costa-Font, 2005).

${ }^{3}$ This aspect has been stressed with the particular aim to provide developing countries affected by endemic diseases, such as HIV/AIDS, and malaria, the necessary policy to tackle their health problems. On the other hand, the U.S. government has recognized the possibility to prevent parallel trade from specific countries (Australia, Morocco, Singapore) by contractual means (Fink and Reichenmiller, 2005). This is also controversial, as preventing parallel trade by means of private contracts could be considered an anticompetitive behavior that prevails under competition law (Gallini and Hollis, 1999).

${ }^{4}$ Parallel trade does not imply necessarily price convergence if consumers do not believe that the original drug and the parallel imported drug have the same value (Jelovac and Bordoy, 2005). Empirical studies in the EU include Ganslandt and Maskus (2004), Kanavos and Costa-Font (2005) and Kyle (2007).
} 
preserving investment in R\&D. Complementary to this perspective, cross-national drug price differentials may not be based on demand elasticity, but on differences in other relevant demand factors (Maskus, 2000). The interference of national governments in private markets by way of regulation of drug prices is, in particular, a factor causing price differences at the international level (Pecorino, 2002; Jelovac and Bordoy, 2005; Saggi, 2013).

A more recent strand of the literature, to which our paper belongs, reassesses the role of parallel trade and focuses on the willingness to invest in R\&D. This is particularly relevant, since normative results regarding parallel imports should ideally come from models in which innovation is accounted for. Welfare can either increase or decrease depending on whether dynamic effects of parallel trade are examined (Valletti and Szymanski, 2006; Valletti, 2006; Grossman and Lai, 2008; Chen and Schwartz, 2013).

An important aspect emerging from the literature is that the patent holder's decision to export is endogenous. Pricing regulations have a significant influence on the entry of firms into foreign markets, especially into less developed countries (Goldberg, 2010). These entry decisions depend on entry costs, as well as on the impact that local regulations might have globally. In our model we introduce explicitly the notion of local delivery costs in the South. The system by which drugs are supplied within a country is an aspect that has a key impact on the final price of drugs, and on their accessibility (WHO, 2002). ${ }^{5}$ Chaudhuri et al. (2006) stress the importance of weak distribution networks in India. They show that, even when multinational patent holders enter developing countries, the distribution and marketing networks of multinationals are limited and costly, so that their products may not be reaching remote rural areas. They also argue that access to drugs and distribution coverage should be a crucial part of any welfare analysis. We follow their spirit and in the next Section we model (costly) access to drugs in the South.

\section{Model assumptions}

As patents create monopoly power in the pharmaceutical industry (indeed, that is their very purpose), a monopoly model with a partial equilibrium framework is a natural set-up within which to analyze the mechanism of IPRs policies. ${ }^{6}$ We start the analysis

\footnotetext{
${ }^{5}$ Lack of public health infrastructures and services constitute an important barrier to the access to drugs for many developing countries (for more details see http://www.unmillenniumproject.org/documents/TF5-medicines-Complete.pdf).

${ }^{6}$ This assumption is standard in the literature that studies parallel trade of patented drugs. See Roy and Saggi (2012) for an alternative approach in an oligopolistic setting. We also do not consider vertical
} 
by considering the strategic interaction between a single innovative firm, based in the unregulated North $(N)$, and a foreign government, located in the South $(S)$. Later, in Section 6 , we endogenize the policy choices of the two countries.

In each country, consumers are heterogeneous, with preferences à la Mussa and Rosen (1978). Specifically, a consumer of type $\tau$ that buys a product of quality $u$ at a price $p$ enjoys a net utility given by:

$$
U(\tau)=\tau u-p
$$

where $\tau$ measures the consumer's marginal valuation of quality. The taste parameter $\tau$ is distributed uniformly over the interval $\tau \in[0,1]$. Consumers can also decide not to buy any supplied good, and in this case they obtain their reservation utility, which is independent of type and normalized to zero. Since the lowest type is 0 , in both countries there will be always someone who does not buy any product, unless it is offered for free. These preferences are simply meant to generate downward demands in both countries: if the price of a drug decreases, more people will have access to it. Similarly, if the quality of a drug increases, ceteris paribus, there is a demand expansion effect.

Notice that, in contrast with previous literature, preferences in each country are identical, so that parallel trade cannot exploit differences in willingness-to-pay per se. We are therefore assuming that there are great disparities of income both in the North and in the South. Similar outcomes would arise with alternative specifications that still resulted in the same elasticity of demand in both countries. This modelling choice is made to abstract from other aspects that have already been investigated by the literature, and thus make our contribution more transparent. ${ }^{7}$

North and South differ in three important respects. First, the good is supplied by the patent holder who is based in the North. By spending resources on $R \& D$, the monopolist can improve the quality of its good, with the cost of quality, denoted as $C(u)$, increasing at an increasing rate, $C^{\prime}(u)>0$ and $C^{\prime \prime}(u)>0$. These are "global" costs which are incurred only at the investment stage. All other costs at the manufacturing stage, after R\&D is sunk, are identical in the North and in the South and are normalized to zero, which is reasonable for the pharmaceutical industry.

The second difference between the North and South stems from distribution costs and access to health services. While the North has a system already in place for distributing, selling, and administering drugs, this does not hold for the South. In particular, we distribution arrangements (see Maskus and Chen, 2004).

${ }^{7}$ Instead of North and South, we could have equally used West and East, or Domestic and Foreign. We keep the $N$ and $S$ notation because it is quite common in the literature this paper belongs to, as well as to highlight differences in distribution costs which are quite natural in the North/South context. 
assume that, when a mass $x$ of consumers is supplied in the South, there are some corresponding "local" costs defined as $L(x)$, increasing at an increasing rate, $L^{\prime}(x)>0$ and $L^{\prime \prime}(x)>0$. To obtain closed-form solutions, we employ the following function:

$$
L(x)=k \frac{x^{2}}{2}
$$

where $k>0$ is a parameter that allows us to describe how costly it is to supply the South. In the North there is a unit mass of customers, while the mass $x$ of consumers supplied in the South varies and is endogenously determined in equilibrium, as it depends on coverage costs. We will show that the impact of parallel trade depends quite crucially on the relative market size of North and South. Hence the specific role of $k$ is to generate differences in the size of the markets: a "small" value of $k$ corresponds to a "large" mass of consumers that are supplied in the South relative to the North, and vice versa. ${ }^{8}$

In other words, because supplying drugs to the least accessible patients in the South implies more delivery costs, the provision of pharmaceuticals to more people becomes progressively more expensive. One interpretation is the following. Imagine that, in the South, there is a certain mass of potential consumers who live in different locations, which are ordered according to a "distance" parameter $x$. This represents how easy or difficult it is to supply and market drugs at that location (e.g., geographic access). Consumers at $x=0$ are those in the biggest city, where it is very easy to supply them (e.g., because basic services are already in place), while to reach, supply and administer drugs to more people in remote regions becomes gradually more expensive for the provider. The model will determine endogenously the equilibrium value of $x$, i.e., the number of people who have access to the drug. Thus, at each location, there is heterogeneity of taste according to (1) (i.e., rich and poor people live both in cities and in rural areas). A multi-dimensional screening problem, whereby $\tau$ and $x$ were somehow correlated, is beyond the scope of this paper.

The third difference concerns the role of governments. We assume that the government in the North does not regulate any aspect of drug production and consumption. The North has adopted a strong system of IPRs that grants a patent to the monopolist for reasons that we do not model but just take as given. Still, as in our model parallel trade will only potentially flow from the South to the North, the North can decide on the international exhaustion of IPRs. We also consider different approaches of the South government in relation to drug price control that we will further specify below. Hence

\footnotetext{
${ }^{8}$ Other than this, there is nothing peculiar about the specific functional form chosen for $L(x)$ which we mainly keep for analytical simplicity.
} 
the strategic players in our model are the monopolist firm, the North government, and the South government.

We proceed in developing the model in several steps. We study two different regulatory regimes on the exhaustion of IPRs. If parallel trade is banned, the firm can, in principle, set a different price in each market, because market segmentation is possible. However, if parallel trade is permitted, the firm is forced to set an identical price both in the North and in the South market, as it would otherwise attract arbitrageurs. For simplicity we assume that arbitrage is perfect and reimportation costs do not exist.

In the following Section, we first examine the simplest model where the South government is also passive and does not regulate drug prices, which are therefore freely set by the patent holder at a monopoly level.

\section{A benchmark: the irrelevance of parallel trade}

Without parallel trade, perfect market segmentation is possible. Both in the domestic and in the foreign market, the patent holder behaves as a monopolist. We solve a twostage game where the monopolist first decides on $R \& D$, and then it sets the price in each market, as well as the coverage in the South.

In each market, there is a marginal type who is just indifferent between buying and not buying, defined as

$$
\underline{\tau}_{i}=p_{i} / u
$$

where $i=N, S$. For future reference, it is also convenient to define consumer surplus in both countries, which is respectively

$$
\begin{aligned}
& C S_{N}=\int_{\underline{\tau}_{N}}^{1}\left(\tau u-p_{N}\right) d \tau=\frac{\left(u-p_{N}\right)^{2}}{2 u}, \\
& C S_{S}=x \int_{\underline{\tau}_{S}}^{1}\left(\tau u-p_{S}\right) d \tau=x \frac{\left(u-p_{S}\right)^{2}}{2 u} .
\end{aligned}
$$

In the last stage, the monopolist sets a price $p_{N}$ in the North and a price $p_{S}$ in the South to maximize its profits

$$
\begin{aligned}
\pi_{N}+\pi_{S} & =\int_{\underline{\tau}_{N}}^{1} p_{N} d \tau+x \int_{\underline{\tau}_{S}}^{1} p_{S} d \tau-L(x) \\
& =p_{N}\left(1-p_{N} / u\right)+p_{S}\left(1-p_{S} / u\right) x-k x^{2} / 2
\end{aligned}
$$


It follows immediately that

$$
p_{N}=p_{S}=p^{*}=\frac{u}{2}
$$

with different profits in each country due to market coverage differences. Indeed, in the North the monopolist makes a profit equal to $\pi_{N}=\frac{u}{4}$ and in the South its profits are $\pi_{S}=\frac{u}{4} x-k \frac{x^{2}}{2}$. The optimal coverage of the South is also immediately derived and equal to

$$
x=\frac{u}{4 k},
$$

which is increasing in quality, as gross profits at each location in the South also increase in quality and, of course, decreasing in $k$, i.e., as delivering drugs to the South entails higher local delivery costs. ${ }^{9}$

In the first stage, the patent holder maximizes its global profits

$$
\Pi=\pi_{N}+\pi_{S}-C(u)=\frac{u}{4}+\frac{u^{2}}{32 k}-C(u) .
$$

The monopolist thus offers both in the North and in the South a good having the same optimal quality $u^{*}$, implicitly defined by

$$
\frac{1}{4}+\frac{u}{16 k}=C^{\prime}(u)
$$

Since the monopolist already sets the same price everywhere, we obtain our first result: parallel trade, despite forcing the monopolist to set a uniform price in every market, obviously has no impact. Thus the monopolist still charges $\widetilde{p}=p^{*}=u / 2$ everywhere, where we use the tilde sign for variables in any regime with parallel trade.

Proposition 1. In the benchmark, parallel trade does not affect the investment decision, and consumer surplus and welfare also are invariant to the exhaustion regime.

The above simple analysis establishes our benchmark. Notice that we framed our approach in terms of a realistic two-stage game where investment choices are prior to the price setting. This timing is inconsequential though, since all decisions are taken by a single decision maker, and parallel trade does not affect optimal pricing. In the next Section we show how parallel trade and the precise timing of moves have instead real effects when the government in the South engages in drug price control.

\footnotetext{
${ }^{9}$ As it becomes apparent below, we assume that the second-order condition w.r.t. $u$ is satisfied at the optimal quality $u^{*}$, for which we require that $k>\underline{k}=1 /\left[16 C^{\prime \prime}\left(u^{*}\right)\right]$. This restriction implies that $x$ is bounded in equilibrium. By also assuming that the total mass of potential customers in the South, $M_{S}$, satisfies $M_{S} \geq u /(\underline{k})$, we can always ensure that the number of consumers that are actually supplied never exceeds the total population of the South.
} 


\section{$5 \quad$ Price cap and commitment}

In this section we analyze the effects produced by the introduction of price regulation in the South. Quite often governments regulate prices with the final aim to benefit consumers while still providing incentives to innovate. ${ }^{10}$ We develop our analysis by assuming that the South government has the ability to set a price cap in its own market. The price cap is chosen by a benevolent government with the aim to maximize the welfare of consumers in its own country alone. What will turn out to be critical for the analysis is the order of moves, which reflects also the South government's commitment when setting the price cap. The complete sequence of moves is shown in Figure 1, where we already anticipate the three different levels of commitment the South government might have, corresponding to its intervention at different points of the time line.

The timing of the game is as follows:

Stage 0 (policy game): The North decides whether or not to allow parallel trade, while the South simultaneously decides on its price commitment level (further described below);

Stage 1: The firm chooses its global R\&D level $u$;

Stage 2: The firm chooses the coverage of the South $x$ (this includes the option of not delivering the drug), as well as the price $p_{N}$ in the North.

As shown in Figure 1, commitment refers to the setting of the price control prior to R\&D ('full commitment'; say at stage 0.5), after R\&D but prior to coverage/delivery choices to the South ('partial commitment'; say at stage 1.5), or after both R\&D and coverage choices ('no commitment'; say at stage 2.5). In any event, after the policy choices are made, a three-stage game is played.

No commitment (NC) We start with the starkest example, where the South government has no commitment at all, and sets its regulated price in the last stage of the game, without anticipating its effects neither on global nor or local investment decisions. Thus, as it is shown in the right branch of Figure 1, we consider the following timing of the game: first the firm invests in $R \& D$, and successively decides the coverage of the South country, as well as the price in the North. Then, in the last stage, the South government sets the price in its own country.

It is immediate to show that the South government, once the good has been invented and delivered to the South, will always have an incentive to set its price as low as possible,

\footnotetext{
${ }^{10}$ For an overview of theory and practice of price regulation in the pharmaceutical sector, see Danzon (1997) and Danzon and Chao (2000).
} 
that is, $p_{S}=0$, as we normalized to zero all manufacturing costs. The monopolist anticipates that no profits will be made in the South, so it decides not to cover any part of it. Global profits are made only from the North, $\Pi=u / 4-C(u)$. The monopolist still invests, but an amount lower than before, as it is now $1 / 4=C^{\prime}\left(u^{N C}\right)$ and thus, compared to (3), it is obvious that $u^{N C}<u^{*}$. Profits and consumer surplus decrease everywhere, especially in the South where there is no supply at all.

Notice that, once again, there is an irrelevance result for parallel trade. In fact, under parallel trade, if the firm supplied the South, the price regulated at zero would apply to the North as well, cannibalizing profits everywhere. Thus, under parallel trade, the firm will decide not to supply the South market, hence achieving the same outcome as without parallel trade, though for a slightly different reason. ${ }^{11}$

Partial commitment (PC) The previous case points to the fact the South government has to give incentives to the firm to be present in its own market, both with and without parallel trade. These incentives arise from restraining its ability to regulate prices and avoid hold-up problems. Therefore we now alter slightly the timing of the game. First, the firm chooses R\&D. Then the government of the South sets its regulated price. Finally, the firm decides the coverage of the South market, as well as the price in the North. This timing endows the foreign government with some commitment capabilities, as in the second stage it acts anticipating the monopolist's local coverage decision. ${ }^{12}$ The complete timing of the events corresponds to the middle branch of Figure 1.

We start first with the case without parallel trade. In the last stage, the firm sets the monopoly price $p_{N}=u / 2$ in the North, while coverage in the South is decided from maximizing $\pi_{S}=p_{S}\left(1-p_{S} / u\right) x-k x^{2} / 2$, that is

$$
x=p_{S} \frac{u-p_{S}}{k u} .
$$

In the second stage, the South government sets the price cap $p_{S}=p_{C}$ that maximizes

\footnotetext{
${ }^{11}$ Some evidence of this can be found in the recent shortage of medicines in Greece: "Companies are ceasing drug supplies because Greece is not profitable for them and they are worried that their products will be exported by traders to other richer countries through parallel trade as Greece has the lowest medicine prices in Europe," said Professor Yannis Tountas, the president of the Greek drug regulator, the National Organisation for Medicines (reported in the Guardian newspaper, see http://www.guardian.co.uk/world/2013/feb/27/greece-blames-drug-companies-shortages).

${ }^{12}$ The way by which governments in Europe and Canada regulate the price of drugs inspires the setup of our partial commitment case. Indeed, the use of price caps along with all policy interventions on price create direct and indirect effects (by means of "external referencing", also known as "global reference pricing") (Goldberg, 2010).
} 


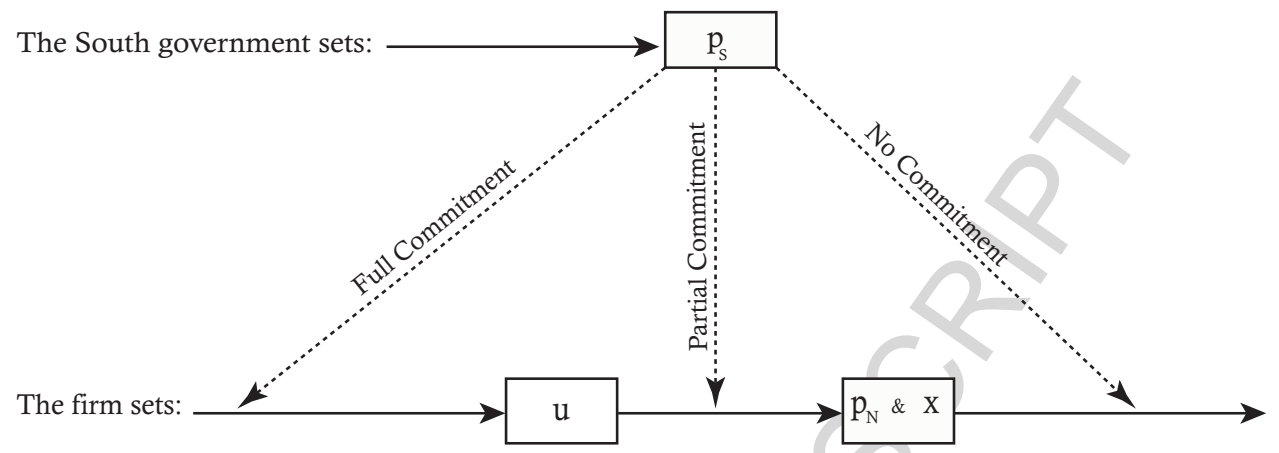

Figure 1: Sequence of moves for different commitment levels

its consumer surplus, given by (2), anticipating the firm's coverage reaction:

$$
C S_{S}=x \frac{\left(u-p_{C}\right)^{2}}{2 u}=\frac{\left(u-p_{C}\right)^{3} p_{C}}{2 k u^{2}}
$$

which results in a price cap of

$$
p_{C}=\frac{u}{4},
$$

that is obviously greater than zero (as otherwise coverage would also be zero), but also lower than the unrestricted monopoly price. From (4), coverage is then $x=3 u / 16 k$.

In the first stage, the monopolist maximizes the global profit

$$
\Pi=\pi_{N}+\pi_{S}-C(u)=\frac{u}{4}+\frac{9 u^{2}}{512 k}-C(u)
$$

from which we obtain a level of quality $u^{P C}$ that satisfies $u^{N C}<u^{P C}<u^{*}$, ${ }^{13}$ i.e., investment is higher compared to the previous case without any commitment, but lower than that in the unregulated case. It also follows that the cap is set at $p_{C}=u^{P C} / 4<p^{*}$.

We now turn to parallel trade. In the last stage, the monopolist anticipates that the price set in the South will determine the price globally, and thus maximizes

$$
\pi_{N}+\pi_{S}=p_{S}\left(1-p_{S} / u\right)(1+x)-k x^{2} / 2
$$

with respect to the coverage in the South, as long as it finds it optimal to supply the South at all. This maximization still gives (4), exactly as in the case without parallel

\footnotetext{
${ }^{13}$ The second inequality derives from comparing $\partial \Pi / \partial u$ with $(3)$, and noting that $18 u / 512 k<u / 16 k$.
} 
trade.

In the second stage, the South government in principle should still set the same price cap as without parallel trade, that is, $p_{S}=p_{C}=u / 4$. However, as the cap applies everywhere, the government of the South must, in addition, ensure that the monopolist is willing to supply the product there. Recall that, in stage 2, quality has already been chosen and investment is sunk. Should the monopolist block sales to the South, it will then sell only in the North at a price $p_{N}=u / 2$ with associated gross profits of $u / 4$. Therefore the South government maximizes

$$
\begin{aligned}
\max _{p_{C}} C S_{S} & =\frac{\left(u-p_{C}\right)^{3} p_{C}}{2 k u^{2}} \\
\text { s.t. } p_{C}\left(1-\frac{p_{C}}{u}\right)(1+x)-\frac{k x^{2}}{2} & =\frac{p_{C}}{2}\left(1-\frac{p_{C}}{u}\right)\left[2+\frac{p_{C}}{k}\left(1-\frac{p_{C}}{u}\right)\right] \geq u / 4 .
\end{aligned}
$$

We can now state the following result (we recall that variables with a tilde sign refer to parallel trade).

Proposition 2. Imagine the South government can partially commit. (i) When the cost of supplying the South is low ( $\left.k \leq k^{P C}\right)$, investment is higher than without commitment but lower than in the benchmark. Parallel trade reduces both investment and the price cap: $u^{N C}<\widetilde{u}^{P C}<u^{P C}<u^{*}$ and $\widetilde{u}^{P C} / 4=\widetilde{p}_{C}<p_{C}=u^{P C} / 4<p^{*}$. (ii) When the cost of supplying the South is high $\left(k>k^{P C}\right)$, parallel trade further reduces investment down to the same level as without any commitment, despite possibly setting a more lenient cap: $u^{N C}=\widetilde{u}^{P C}<u^{P C}<u^{*}$ and $\widetilde{u}^{P C} / 4<\widetilde{p}_{C}, p_{C}=u^{P C} / 4$, with $\widetilde{p}_{C}>p_{C}$ for very high values of $k$.

Proof. The solution to (6) is simply the unconstrained solution $\widetilde{p}_{C}=u / 4$ (which is the same expression as without parallel trade, though the equilibrium qualities might differ) if the constraint is not binding, which can be rewritten as $\frac{3 u}{16}+\frac{9 u^{2}}{512 k} \geq \frac{u}{4}$. This does not bind if $k$ is low enough. Otherwise it amounts to setting the lowest price that makes the firm's participation condition just binding. The solution then is

$$
\widetilde{p}_{C}=\left\{\begin{array}{c}
\frac{u}{4} \text { iff } k \leq \frac{9 u}{32}, \\
\frac{1}{2}\left(u-\sqrt{4 k u+u^{2}-2 u \sqrt{2 k(2 k+u)}}\right)>\frac{u}{4} \text { iff } k>\frac{9 u}{32} .
\end{array}\right.
$$

Under the parallel trade regime, $p_{N}=p_{S}=\widetilde{p}_{C}$ implies a global profit

$$
\Pi=\pi_{N}+\pi_{S}-C(u)=\left\{\begin{array}{c}
\frac{u}{4}-C(u) \text { iff } u<\frac{32}{9} k, \\
\frac{3 u}{16}+\frac{9 u^{2}}{512 k}-C(u) \text { iff } u \geq \frac{32}{9} k .
\end{array}\right.
$$


Compared to (5), the solution therefore is $u^{N C}<\widetilde{u}^{P C}<u^{P C}$, and thus $\widetilde{p}_{C}=\widetilde{u}^{P C} / 4<$ $p_{C}=u^{P C} / 4$, when $k \leq k^{P C}$. When $k>k^{P C}$, it is $\widetilde{u}^{P C} \equiv u^{N C}$. The function $\Pi$ is single-peaked in $u$ for low and for high values of $k$. Instead, for values of $k$ close to the threshold $k^{P C}$, it is double-peaked. The optimal investment is found on the right branch of the profit function, until $k^{P C}$ is reached, where $k^{P C}$ is defined from $\frac{u^{N C}}{4}-C\left(u^{N C}\right) \equiv \frac{3 \widetilde{u}^{P C}}{16}+\frac{9\left(\widetilde{u}^{P C}\right)^{2}}{512 k^{P C}}-C\left(\widetilde{u}^{P C}\right)$. For sure, $k^{P C}>\frac{9 u^{N C}}{32}$. We also note that, close to the threshold value $k^{P C}$, then from $(7) \widetilde{p}_{C}$ is set above but still very close to $u / 4$ and the prevailing effect is the reduction in quality arising from lower profits in the North: $\widetilde{p}_{C}<p_{C}$. When instead $k$ is very high the inequality is reversed. To show this, take the limiting case $k \rightarrow \infty$ : from (5) without parallel trade it is $u^{P C} \rightarrow u^{N C}$, with $p_{C}=u^{P C} / 4$. Under parallel trade, from (7), it is $\widetilde{p}_{C} \rightarrow \widetilde{u}^{P C} / 2$, with $\widetilde{u}^{P C}=u^{N C}$. Hence $\tilde{p}_{C}>p_{C}$ for high enough values of $k$. QED

Proposition 2 shows that there are now real effects from parallel trade, which are further investigated with the help of Figure 2. The four panels plot the differences of several key variables, with and without parallel trade, as a function of $k$, under a quadratic investment function, $C(u)=u^{2} / 2$. These variables are respectively: invested quality, price cap, consumer surplus in the South, and global welfare (defined as the sum of consumer surplus in the two countries and the firm's profits). Recall that the role of the parameter $k$ is to change the South coverage costs, and therefore vary endogenously the market size of the South relative to the North: low (high) values of $k$ corresponds to a large (small) South in equilibrium.

We start the discussion when supplying the South is not very costly $\left(k \leq k^{P C}=\right.$ $\left.\frac{9}{112} \simeq 0.08\right),{ }^{14}$ which means that the South is a large market and participation is not at stake, since the monopolist is willing to supply the South even at the price cap, under either exhaustion regime. The unconstrained price cap set in the South applies globally under parallel trade, which depresses investment (top left panel). The price cap is set at the unconstrained level $u / 4$ both with and without parallel trade, but parallel trade lowers $u$ and thus the cap as well (top right panel). Consumers surplus in the South is lower under parallel trade because of the negative impact on quality (bottom left panel). Price regulation in the South benefits consumers in the (unregulated) North under parallel trade. However, for low $k$, the South is relatively larger, and therefore global welfare still largely follows the same behavior as consumer surplus in the South (bottom right panel).

\footnotetext{
${ }^{14}$ This threshold value comes from equating, in the specific case with quadratic investment $C(u)=\frac{u^{2}}{2}$, $\frac{u^{N C}}{4}-C\left(u^{N C}\right)=\frac{1}{32}$ with $\frac{3 \widetilde{u}^{P C}}{16}+\frac{9\left(\widetilde{u}^{P C}\right)^{2}}{512 k^{P C}}-C\left(\widetilde{u}^{P C}\right)=\frac{9 k}{512 k-18}$.
} 

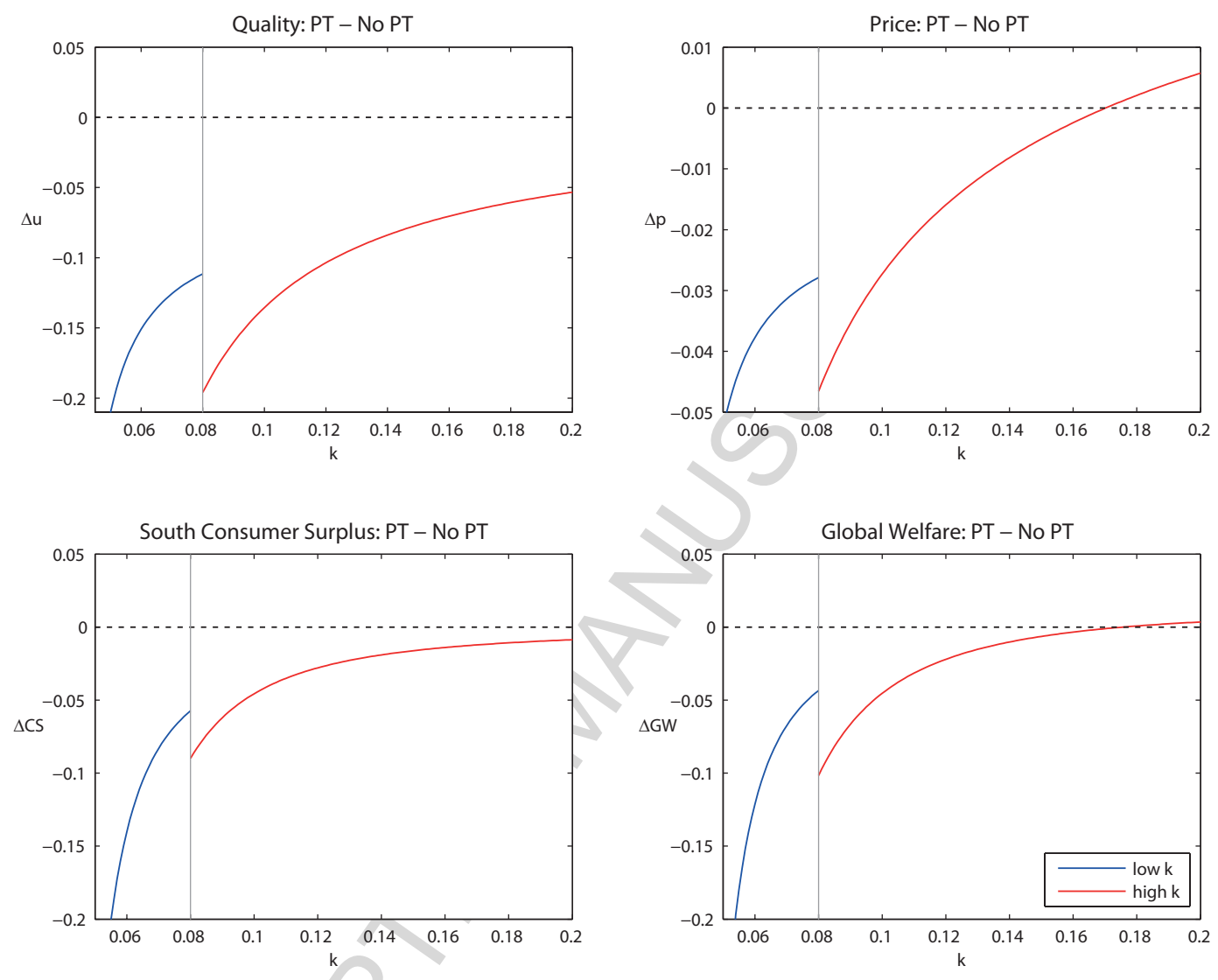

Figure 2: Partial Commitment - Parallel Trade vs No Parallel Trade

When $k$ is large $\left(k>k^{P C}\right)$, instead, incentives must be given to induce the firm to supply the (relatively small) South. As shown by Proposition 2, parallel trade further reduces investment down to the lowest level as without any commitment at all (the difference with and without parallel trade shrinks as $k$ increases, since the South becomes less and less relevant; see the top left panel for large values of $k$ ). The price cap always benefits consumers in the North who would otherwise be charged the monopoly price $p^{*}$. This explains why, when $k$ is sufficiently large and the North has a bigger weight, global welfare increases (the difference fades away when $k \rightarrow \infty$, which is not shown in the range considered in the bottom right panel of Figure 2).

Full commitment (FC) We now consider the possibility that the foreign government behaves differently. With the purpose of increasing its reputation, the government of the South is committed to set a price regulation that anticipates its full effects not only on the 
local market coverage, but also on the global investment in R\&D. Such precommitment is the timing specifically considered in Grossman and Lai (2008), although our models differ in several other respects. Hence the game now has the following timing. The government of the South gets to move first and sets the price cap in its own market. Then the monopolist observes the price cap and chooses the amount of R\&D investment. Finally, the monopolist sets the price in the unregulated market (in the absence of parallel trade), as well as the market coverage in the South. The left branch of Figure 1 displays the complete timing of the game.

Without parallel trade, solving by backward induction, in the last stage the firm sets $p_{N}=u / 2$ in the North achieving a profit $\pi_{N}=u / 4$, while the South market coverage is the same as in the case with partial commitment, that is (4).

In the second stage, the monopolist chooses the optimal level of R\&D by maximizing its global profits

$$
\Pi=\frac{u}{4}+\frac{\left[p_{S}\left(1-p_{S} / u\right)\right]^{2}}{2 k}-C(u),
$$

from which we obtain

$$
\frac{\partial \Pi\left(p_{S}, u\left(p_{S}\right)\right)}{\partial u}=\frac{1}{4}+\frac{p_{S}^{3}}{k u^{2}}\left(1-\frac{p_{S}}{u}\right)-C^{\prime}(u)=0,
$$

which characterizes implicitly the optimal investment $u\left(p_{S}\right)$ as a function of $p_{S}$.

At the first stage, the maximization problem of the South government amounts to setting a price cap $p_{S}=p_{C}$ to maximize

$$
\max _{p_{C}} C S_{S}=\frac{\left[u\left(p_{C}\right)-p_{C}\right]^{3} p_{C}}{2 k u\left(p_{C}\right)^{2}} .
$$

Proposition 3. Imagine the South government can fully commit and there is no parallel trade. It is always more costly (i.e., a less stringent cap is needed) to elicit the same investment than under partial commitment. (i) When $k>3 /\left[16 C^{\prime \prime}\left(u^{F C}\right)\right]$, it is always $u / 4<p_{C}<p^{*}$; it is also $u^{N C}<u^{F C}<u^{P C}<u^{*}$ if $k$ is high enough. (ii) When $k \leq 3 /\left[16 C^{\prime \prime}\left(u^{F C}\right)\right]$, it is always $u^{F C}=u^{*}>u^{P C}>u^{N C}$ and $p_{C}=p^{*}$.

Proof. The first-order condition for the South is

$$
\begin{aligned}
\frac{d C S_{S}}{d p_{C}} & =\frac{\partial C S_{S}}{\partial p_{C}}+\frac{\partial C S_{S}}{\partial u} \frac{d u}{d p_{C}} \\
& =\frac{\left(u-p_{C}\right)^{2}\left(u-4 p_{C}\right)}{2 k u^{2}}+\frac{\left(u-p_{C}\right)^{2} p_{C}\left(u+2 p_{C}\right)}{2 k u^{3}} \frac{d u}{d p_{C}}=0 .
\end{aligned}
$$


Suppose first that the South government wants to get a certain level $u$ of quality. From (9), the first term is zero for $p_{C}=u / 4$, which is the same cap set under PC. The sign of the second term depends on the sign of $\frac{d u}{d p_{C}}$. By implicit differentiation of (8) we obtain

$$
\frac{d u}{d p_{C}}=-\frac{\partial^{2} \Pi / \partial u \partial p_{S}}{\partial^{2} \Pi / \partial u^{2}}=\frac{u p_{C}^{2}\left(3 u-4 p_{C}\right)}{k u^{4} C^{\prime \prime}+p_{C}^{3}\left(2 u-3 p_{C}\right)}>0,
$$

since the price will be at most $p^{*}=u / 2$. Hence we obtain that $p_{C}>u / 4$. Alternatively, imagine that the South sets the same price cap as under PC, $p_{C}=u / 4$. Then from (8) the marginal incentive to supply quality is $\frac{1}{4}+\frac{3 u}{256 k}$ which is strictly lower than the incentive, for the same price cap level, under PC, which is obtained from (5) and amounts to $\frac{1}{4}+\frac{9 u}{256 k}$.

Consider now the impact on $C S_{S}$ when the South chooses the unregulated price, $p_{C}=p^{*}$. As $\frac{d u}{d p_{C}}$ simplifies to $\frac{4}{1+16 k C^{\prime \prime}}$, we obtain

$$
\left.\frac{d C S_{S}}{d p_{C}}\right|_{p_{C}=p^{*}}=\frac{u\left(3-16 k C^{\prime \prime}\right)}{8 k\left(1+16 k C^{\prime \prime}\right)} .
$$

If $k>3 /\left[16 C^{\prime \prime}\left(u^{F C}\right)\right]$, then $p_{C}<p^{*}$. In the limit, as $k \rightarrow \infty$, it is $\frac{d u}{d p_{C}} \rightarrow 0$ and $p_{C}=u / 4$. Together with the previous finding, this proves that $u^{F C}<u^{P C}$ for very high values of $k$. If instead $k$ is close to $3 /\left[16 C^{\prime \prime}\left(u^{F C}\right)\right]$, then $p_{C}$ is close to $p^{*}$ and investment will approach $u^{F C}=u^{*}>u^{P C}$.

If $k \leq 3 /\left[16 C^{\prime \prime}\left(u^{F C}\right)\right]$, then (9) is always positive at $p=p^{*}$. Hence the South will set $p_{C}=p^{*}$ and achieve $u^{F C}=u^{*}>u^{P C}$. QED

Essentially, when $k$ is small, investment is very responsive to price regulation, which becomes more lenient. In fact, the best the South government can do is not to regulate at all, in which case we fall back into the unregulated benchmark. Hence, despite having a full commitment ability, the South uses it by withdrawing regulation entirely. If instead investment is not too responsive to price regulation (which happens when the relative size of the South is small as the cost of supplying it is very large), then the South government will want to set a binding price cap. In the limit, when $k$ is made arbitrarily large, it would set the same price cap as under partial commitment: however this will achieve a strictly lower investment because, under full commitment, R\&D costs are not yet sunk and it is now more difficult to elicit investment.

Now we imagine that parallel trade is permitted. The game takes the same timing as without parallel trade. As above, at the third stage the monopolist defines the South market coverage. In the second stage, the firm determines its R\&D investment according 
to the following maximization problem:

$$
\begin{aligned}
\max _{u} \Pi=(1+x) p_{C}\left(1-\frac{p_{C}}{u}\right)-k \frac{x^{2}}{2}-C(u) \\
\text { s.t. } x=p_{C} \frac{u-p_{C}}{k u} .
\end{aligned}
$$

This leads to the following first-order condition

$$
\frac{\partial \Pi\left(p_{C}, u\left(p_{C}\right)\right)}{\partial u}=\frac{p_{C}^{2}}{u^{2}}+\frac{p_{C}^{3}}{k u^{2}}\left(1-\frac{p_{C}}{u}\right)-C^{\prime}(u)=0,
$$

which characterizes the optimal investment $u\left(p_{C}\right)$ as a function of price set by the government of the South.

In the first stage, the South government defines the price cap, anticipating the monopolist's investment decision in $R \& D$ while still ensuring delivery into the South. If the firm refuses to supply the South, the firm can ensure a payoff equal to the case without commitment, whereby only the North is supplied at the monopoly price. Thus, the problem of the government of the South becomes

$$
\begin{aligned}
\max _{p_{C}} C S_{S} & =\frac{\left[u\left(p_{C}\right)-p_{C}\right]^{3} p_{C}}{2 k u\left(p_{C}\right)^{2}} \\
\text { s.t. } \Pi \geq & \geq \frac{u^{N C}}{4}-C\left(u^{N C}\right) .
\end{aligned}
$$

Proposition 4. Imagine the South government can fully commit and there is parallel trade. When $C(u)$ is not too convex, the South government always withdraws regulation, so that $\widetilde{p}_{C}=p^{*}$ and $\widetilde{u}^{F C}=u^{*}$. Parallel trade weakly increases investment compared to its absence, and strictly so when $k$ is high enough.

Proof. The (unconstrained) first-order condition still takes the form as in (9) where $\frac{d u}{d p_{C}}$ is now derived from (10), leading to

$$
\frac{d u}{d p_{C}}=\frac{u p_{C}\left(2 k u+3 u p_{C}-4 p_{C}^{2}\right)}{k u^{4} C^{\prime \prime}+2 p_{C}^{3} u-3 p_{C}^{4}+2 p_{C}^{2} k u} .
$$

We obtain that, at the unregulated price, it is

$$
\left.\frac{d C S_{S}}{d p_{C}}\right|_{p_{C}=p^{*}}=\frac{u\left(8 k+3 u-16 k u C^{\prime \prime}\right)}{8 k\left(8 k+u+16 k u C^{\prime \prime}\right)} .
$$

At $p_{C}=p^{*}$ we can also simplify the monopolist's FOC (10) that becomes the same as 
(3) which we re-write as

$$
k=\frac{u}{4\left[4 C^{\prime}(u)-1\right]},
$$

where it must hold that $C^{\prime}>1 / 4$. We substitute this expression and finally get

$$
\left.\frac{d C S_{S}}{d p_{C}}\right|_{p_{C}=p^{*}}=\frac{\left(4 C^{\prime}-1\right)\left(12 C^{\prime}-1-4 u C^{\prime \prime}\right)}{8 C^{\prime}+2+8 u C^{\prime \prime}}
$$

The first bracket at the numerator is always positive. The second bracket can be written as $4 C^{\prime}-1+4\left(2 C^{\prime}-u C^{\prime \prime}\right)$, which is always positive as long as $C^{\prime \prime}$ is not too convex. ${ }^{15}$ At this price the participation constraint does not bind, since the monopolist earns profits as in the unregulated benchmark, strictly more than with no commitment. Notice that, even if it were feasible and the South tried to force a price above $p^{*}$ (but in the South alone), then parallel trade would make this policy ineffective as the price $p^{*}$ set in the North would apply in the South too. Hence the South government can just withdraw regulation and achieve the benchmark.

Contrasting these results with the previous Proposition 3, we derive that, when $k>3 / 16 C^{\prime \prime}$, parallel trade increases investment: $\widetilde{u}^{F C}>u^{F C}$. Instead when $k \leq 3 / 16 C^{\prime \prime}$, parallel trade achieves the same level of investment. QED

Our main result is that the effects of parallel trade change dramatically under partial and full commitment. Parallel trade can have the effect of causing more rather than less investment only under full commitment, and when $k$ is high enough. Indeed, when $k$ is low, the impact of the South on global investment is so large that it is better for its government to withdraw any regulation, both with and without parallel trade. Parallel trade therefore has no impact as preferences are identical at every location in our model.

It is when $k$ is high enough that parallel imports achieve more investment: when the South is insulated, its government would want to regulate the local price, reducing investment, compared to the case with parallel trade when it is optimal to leave the monopolist unregulated. For the same reason, parallel trade always increases the price cap when $k$ is high enough: only without parallel imports price cap regulation would in fact be binding. In other words, when serving the South is costly (for high values of $k$ ), in order to secure the delivery of the drugs, the South government needs to become less stringent on price regulation, which under parallel trade case has global effects.

In Figure 3 we plot again some key variables as a function of $k$, now for the full commitment case. The contrast with Figure 2 under partial commitment is quite stark.

\footnotetext{
${ }^{15}$ For instance, if one uses a power function $C(u)=u^{\alpha} / \alpha$, a sufficient condition for the expression to be non-negative is $\alpha \leq 3$.
} 

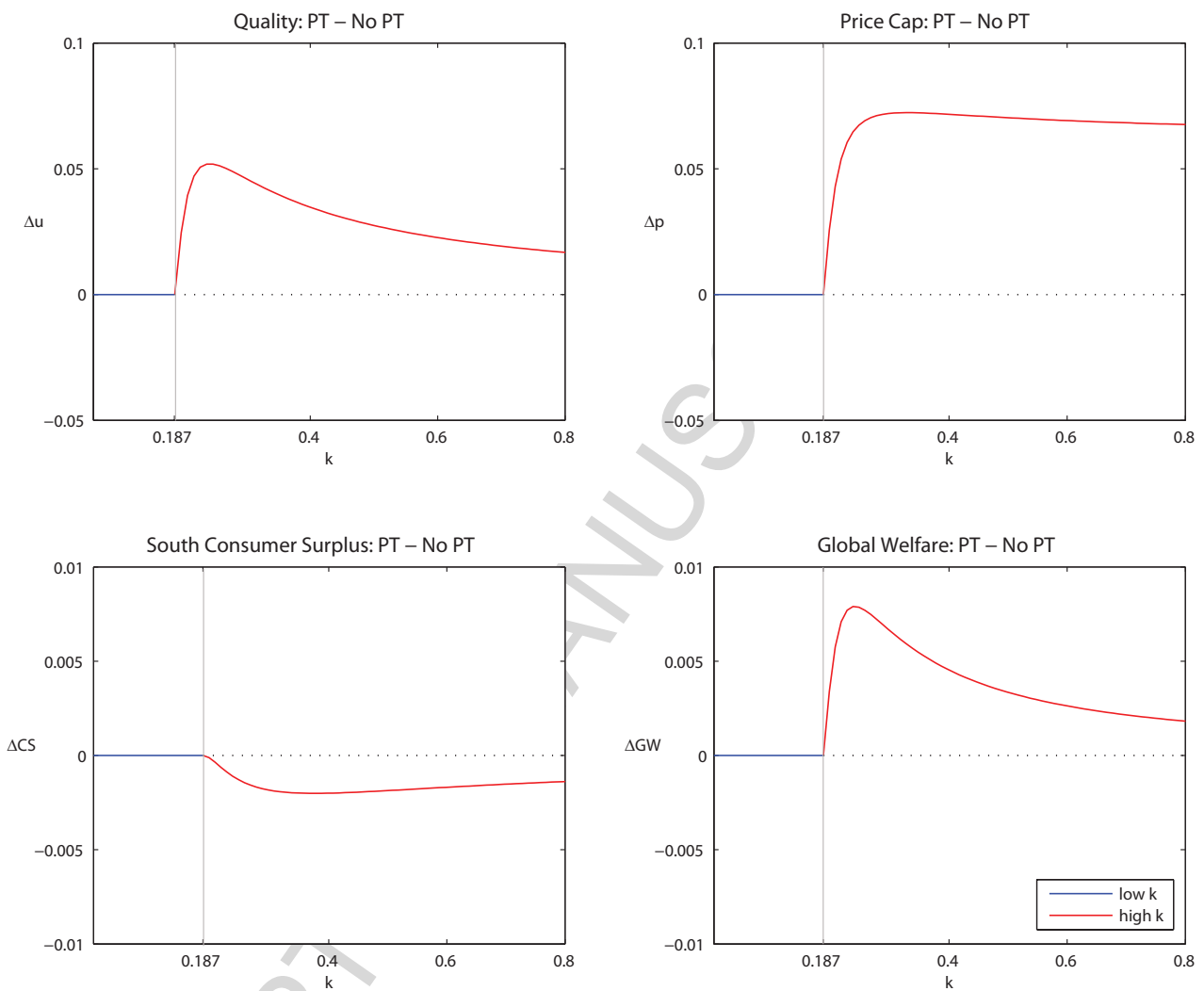

Figure 3: Full Commitment - Parallel Trade vs No Parallel Trade

When the cost of supplying the South market is large $(k>3 / 16=0.1875)$, the government regulates its price only without parallel trade and elicits less investment. In this range, the North, which carries a big weight compared to a relatively small South, is always left unregulated. Hence the North (and global welfare when $k$ is large) strictly benefits from parallel trade, not because the price regulation in the South is 'exported' into the North, but because of the investment effect.

\section{Policy game}

Having considered each case in turn, we now derive equilibrium policies at stage 0 , resulting from the simultaneous choices of the North and South governments. The North decides whether or not to allow parallel imports (as this is, in our model, the 
only possible direction of trade due to price differences). We recall that the North has a patent system in place, which we take as given and we abstract from its optimality. However, this strong IPRs protection does not imply that the North cannot choose a system of international exhaustion that would allow parallel imports. In fact, the TRIPs agreement has taken a neutral position with regard to parallel traded goods, leaving each WTO member with no constraints in deciding whether parallel imports should or should not be blocked. European countries have, for instance, a system where patent protection is enforced alongside the existence of parallel imports within the EU (regional exhaustion). While Japan and Australia have a system which grants patent, they have opted for the international exhaustion regime allowing parallel imports from any foreign country. The US, instead, pursues national exhaustion for patented goods, prohibiting parallel imports.

The South chooses its degree of price commitment, in an attempt to solve the classical time inconsistency problem deriving from its regulations. Unless the government of the South is credibly committed to some price regulation policy, its announcement has little effect. While it is clear that the South will try as much as possible to forgo the fully discretionary policy with no commitment at all, as otherwise the drug will never be delivered to its country, it is not immediately clear what gains it can earn from full or partial commitment capabilities. These differential gains also depend on the choice about the regime of parallel trade selected by the North, as the South then reacts by regulating prices differently too.

In the simultaneous policy game, each government chooses the specific policy intervention in order to maximize its own national welfare, respectively total welfare in the North (where the firm is based) and consumer surplus for the South. Because a full discretionary policy is a strictly dominated strategy for the South, we can immediately rule this case out.

If the North decides to ban parallel imports, the monopolist is able to set an unrestricted monopoly price in the home country, dealing with the regulated price in the South only. As we know from Section 5, this would harm the innovation process unless, under the full commitment case, the relative size of the South is large enough to influence global investments, so that the government is induced to withdraw any regulation. Instead, by making parallel trade legal, the North may increase its consumer surplus to the detriment of patent protection, although much depends again on the South government's decision on its commitment level.

While trade-offs are quite transparent, and can be analyzed in general, we now turn our attention to the equilibrium solutions for the policy game at stage zero using a 
quadratic investment $\operatorname{costs} C(u)=\frac{u^{2}}{2}$. This allows us to compute closed-form solutions, which are easier to discuss.

The following proposition finds the equilibria, as a function of different values of $k$.

Proposition 5. The Nash equilibria of the policy game are as follows:

- i) for high levels of $k(k>0.335)$, it is $\{P T, P C\}$ and the South imposes a strict price control;

- ii) for intermediate and low levels of $k(k<0.335)$, it is $\{P T, F C\}$ and the South withdraws any price control;

- iii) for low levels of $k(k<0.154)$, there is an additional $N E,\{N P T, F C\}$, which is identical to $\{P T, F C\}$ as the South withdraws any price control and therefore there is no room for parallel trade.

Proof. See Web Appendix.

Several interesting results are summarized in Proposition 5. First, as the South chooses some degree of commitment, and this is credible, the North always reacts by allowing parallel trade. In fact, since price regulations are not as strict as without commitment, the North does not fear the destructive implications of a regime of international exhaustion of IPRs. On the contrary, it can gain from it for two different mechanisms. When $k$ is high (and the South therefore is small in size), the South still regulates the price, which reduces investment but only by a little as the South is indeed small. The North in this case benefits from 'importing' price regulation from the South. When $k$ instead is smaller, the North still allows parallel trade but for a new reason: without parallel trade, price control in the South would have no price impact in the North (where the monopoly price is set), and the North would suffer from reduced R\&D. By allowing, instead, parallel trade, this triggers a response in the South that withdraws any control: the North would still be served at the monopoly price, but R\&D strictly increases.

The second interesting result concerns the policy choice of the South. While, at first sight, one would expect that full commitment should generate more benefits to the South than partial commitment, it turns out that this is true only when $k$ is small. When $k$ is large, instead, the South is strictly better off by committing only partially, i.e., setting price controls that ensure delivery to the South but do not take into account $\mathrm{R} \& \mathrm{D}$ expenditures. This is particularly evident under parallel trade, which is chosen by the North: under full commitment the best the South can do is to withdraw regulation, 
as otherwise too little investment would occur. Instead, under partial commitment, the South prefers to set a binding cap, which reduces investment (but just a little when $k$ is high) but also improves affordability.

This result on partial commitment is the more interesting as we have not discussed any additional costs that the South government might have to incur in order to achieve commitment. Under the reasonable assumption that it might be more costly to achieve full rather than partial commitment, our finding is robust and would extend to a wider range of parameters. To put it differently, it follows from our analysis that the South, when relatively small in size, should not spend additional resources to achieve full commitment. Of course, as $k$ gets smaller and the size of the South increases, its impact on $R \& D$ becomes more and more relevant, until the South changes its policy choice and prefers full commitment as it anticipates its impact on global R\&D. This becomes the optimal response to the North having permitted parallel trade.

Being able to commit before the firm's choice on distribution is a point that has been highlighted in the policy literature. The ability of the government to be credibly committed in advance allows the monopolist to reduce the risk related to new $R \& D$ investments, promoting thus the disclosure of critical new treatments, e.g., vaccines (Berndt et al., 2007). ${ }^{16}$ In order to skip the government's temptation to set a price which covers only the manufacturing costs and not the research costs, the foreign government needs to commit itself to a minimum price per dose of drugs, for a certain amount of individuals being immunized.

It is worth emphasizing the importance of Proposition 5 in qualifying the results of Grossman and Lai (2008). They do not analyze our policy game, and assume a timing corresponding to our full commitment case. We have found that their results are indeed very robust when the South is large in size, as full commitment emerges as an equilibrium choice. When instead it is relatively small, full commitment is replaced by partial commitment, and welfare properties change considerably.

We conclude by considering the welfare properties of the Nash equilibria illustrated in Proposition 5. Global welfare is given by the sum of welfare in each country. It turns out that the private equilibrium arising from the policy game is also efficient both when $k$ is high (when $\{P T, P C\}$ is chosen) and when $k$ is small (when $\{P T, F C\}$ is chosen, or $\{N P T, F C\}$ which is observationally equivalent). It is only for intermediate levels of $k$ that there is an interval where there may be over-commitment by the South.

\footnotetext{
${ }^{16} \mathrm{On}$ this regard different proposals have been advanced. For more details see http://www.gavialliance.org/funding/pneumococcal-amc/. A successful example of a high level of commitment can be found in the regional negotiations adopted by eastern Caribbean countries (see http://www.unmillenniumproject.org/documents/TF5-medicines-Complete.pdf).
} 
In particular, under a policy of international exhaustion, for $0.25<k<0.335$, global welfare would be higher under partial commitment, where the South introduces its price control before market coverage is defined, but after the investment in quality has been chosen, while instead it chooses full commitment. This is because the South, which determines the level of commitment, does not internalize its effect on the North, where in this range it would be better to have some level of price regulation, instead of having, as a result of the full commitment choice, the monopoly price everywhere.

\section{$7 \quad$ Summary and conclusions}

The exhaustion of intellectual property rights introduced by the TRIPs agreement represents one of the most controversial issues in the debate over the protection of IPRs, especially in the pharmaceutical sector. Providing a complete welfare analysis, this paper offers insights into the role of these international exhaustions, with a focus on R\&D incentives.

We studied a stylized North-South model which investigates the interactions between government interventions, accounting for parallel trade. Our model is deliberately simplified, assuming identical preferences in each country, invalidating any effect of parallel imports in the absence of government regulation. We concentrated instead on the interaction between international exhaustion and price regulation. We also accounted for dynamic benefits arising from investments. In particular, we drew a distinction between "global" R\&D investments, which determine the quality of a drug everywhere, as opposed to "local" investments, which relate to supply decisions in the South. Because of weak infrastructure and skills, access to drugs for people living in remote areas of the South is limited by high local costs that can discourage the monopolist.

The model that we used is simple and tractable, yet quite rich in the results that it achieves. We considered different timings of the game, capturing the extent to which the South government is able to influence local market coverage (partial commitment), or even anticipate its impact on the quality level of the drug (full commitment). Indeed, the standard hold-up problem can be overcome if the government of the South has some commitment ability. Specifically, when the foreign government introduces price regulation to reduce the price of patented goods, we have found that parallel trade can produce contrasting effects on investment. Under the partial commitment case, when local delivery investments are accounted for by the South, but global R\&D investment is still considered as sunk, parallel trade unambiguously reduces R\&D investment. When the South government defines its price policy before the investment in R\&D is set (full 
commitment), thus anticipating its effect both locally and globally, we have found that parallel trade plays no role if the cost to supply the South market is low: the South government always prefers to renounce any regulation in any case. If instead supplying the South market is costly, the government of the South still withdraws regulation when its price applies globally, while it would set a more stringent regulation if its market was insulated: this clarifies the circumstances under which parallel trade, despite weakening IPRs, can actually create higher incentives to conduct R\&D.

We showed that, in a policy game, parallel trade always emerges in equilibrium in our model. As long as the South achieves some credible degree of price commitment, there is never the possibility of parallel trade having destructive effects on innovation. International exhaustion is therefore chosen by the North as it can then benefit either from reduced prices, or from increased quality. As to the choice of the South, we showed that this depends on its size. When it is relatively small, it will not take into account the impact on global R\&D in its price controls, but it will only ensure an appropriate coverage of the South. If instead the South is large, anticipating also that international exhaustion is chosen by the North, the South chooses a full commitment regime that withdraws price regulations, as it can elicit the highest $R \& D$ efforts in this way.

Our results go beyond the specific case of parallel imports. In fact, parallel trade is only one way of weakening IPRs, which can affect the ability of the drug manufacturer to sustain international price differences. In April 2013, for instance, India's Supreme Court rejected Novartis' attempt to extend patent protection for Gleevec, a major cancer drug. Novartis reacted by announcing that it would have to carefully evaluate whether to launch new drugs in India in the future. ${ }^{17}$ Our results are indeed still valid for any regulations in the South that have country spillovers. This makes government policies interdependent and forces every government to consider the consequences of its actions on global incentives to invest.

\footnotetext{
${ }^{17}$ See, e.g., http://online.wsj.com/article/SB10001424127887323296504578395672582230106.html
} 


\section{References}

[1] Berndt, E.R., Glennerster, R., Kremer, M.R., Lee, J., Levine, R., Weizsäcker, G., Williams, H. (2007), "Advance market commitments for vaccines against neglected diseases: estimating costs and effectiveness", Health Economics, 16, pp. 491-511.

[2] Chaudhuri, S., Goldberg, P., Jia, P. (2006), "Estimating the effects of global patent protection in pharmaceuticals: a case study of quinolones in India", American Economic Review, 96, pp. 1477-1514.

[3] Chard, J.S., Mellor, C.J. (1989), "Intellectual Property Rights and Parallel Imports", World Economy, 12(1), pp. 69-83.

[4] Chen, Y., M. Schwartz (2013), "Differential Pricing When Costs Differ: A Welfare Analysis," mimeo.

[5] Danzon, P.M. (1997), "Price Discrimination for Pharmaceuticals: Welfare Effects in the US and the EU", International Journal of Economics of Business, 4(3), pp. 301-321.

[6] Danzon, P.M., Chao, L.-W. (2000), "Does regulation drive out competition in pharmaceutical markets?", Journal of Law \& Economics, 43, pp. 311-357.

[7] Danzon, P.M., Towse, A. (2003), "Differential Pricing for Pharmaceuticals: Reconciling Access, R\&D and Patents," Journal of Health Care Finance and Economics, 3, 183-205.

[8] Fink, C., Reichenmiller, P. (2005), "Tightening TRIPS: The Intellectual Property Provisions of Recent US Free Trade Agreements", World Bank Trade Note No. 20.

[9] Gallini, N., Hollis, A. (1999), "A contractual approach to the gray market", International Review of Law and Economics, 19, pp. 1-21.

[10] Ganslandt, M., Maskus, K.E. (2004), "Parallel imports and the pricing of pharmaceutical products: Evidence from the EU", Journal of Health Economics, 23, pp. 1035-1057.

[11] Goldberg, P.K. (2010), "Intellectual property rights protection in developing countries: the case of pharmaceuticals", Journal of the European Economic Association, 8, pp. 326-53.

[12] Grossman, G.M., Lai, E.L.C. (2008), "Parallel Imports and Price Control", RAND Journal of Economics, 39(2), pp. 378-402.

[13] Jelovac, I., Bordoy, C. (2005), "Pricing and welfare implications of parallel imports in the pharmaceutical industry", Inter. Journal of Health Care Finance and Economics, 5, 5-21. 
[14] Kanavos, P., Costa-Font, J. (2005), "Pharmaceutical parallel trade in Europe: stakeholder and competition effects", Economic Policy, 20(44), pp. 751-798.

[15] Kyle, M. (2007), "Pharmaceutical Price Controls and Entry Strategies", Review of Economics and Statistics, 89(1), pp. 88-99.

[16] Kyle, M. (2009), "Parallel Trade in Pharmaceuticals: Firm Responses and Competition Policy," in B. Hawk (Ed.), International Antitrust Law \& Policy: Fordham Competition Law, Juris Publishing, New York.

[17] Li, C., Maskus, K.E. (2006), "The Impact of Parallel Imports on Investment in CostReducing R\&D", Journal of International Economics, 68, pp. 443-455.

[18] Malueg, D.A., Schwartz, M. (1994), "Parallel Imports, Demand Dispersion, and International Price Discrimination", Journal of International Economics, 37, pp. 167-196.

[19] Maskus, K.E. (2000), Intellectual Property Rights in the Global Economy, Institute for International Economics, Washington DC.

[20] Maskus, K.E., Chen, Y. (2004), "Vertical pricing and parallel imports: theory and evidence", Review of International Economics, 12, pp. 419-436.

[21] Mussa, M., Rosen, S. (1978), "Monopoly and product quality", Journal of Economic Theory, 18(2), pp. 301-317.

[22] Pecorino, P. (2002), "Should the US Allow Prescription Drug Reimports from Canada?", Journal of Health Economics, 21, pp. 699-708.

[23] Roy, S., Saggi, K. (2012), "Equilibrium Parallel Import Policies and International Market Structure," Journal of International Economics, 87, pp. 262-276.

[24] Saggi, K. (2013), "Market power in the global economy: the exhaustion and protection of intellectual property", Economic Journal, 123, pp. 131 - 161.

[25] Valletti, T.M. (2006), "Differential Pricing, Parallel Trade, and the Incentive to Invest", Journal of International Economics, 70, pp. 314-324.

[26] Valletti, T.M., Szymanski, S. (2006), "Parallel Trade, International Exhaustion and IPRs: A Welfare Analysis", Journal of Industrial Economics, 54(4), pp. 499-526.

[27] WHO (2002), Medicines strategy 2000-2003: framework for action in essential drugs and medicines policy, World Health Organization, Geneva. 
Pharmaceutical Innovation and Parallel Trade - Highlights

- A drug manufacturer in the North may export its good to a price-regulated South

- We discuss the impact of the international exhaustion of IPRs (parallel trade)

- When the South is large, it does not regulate and R\&D increases under parallel trade

- When the South is small, there is regulation and R\&D decreases under parallel trade

- Under parallel trade, the North benefits either from higher quality or lower prices 